\title{
Remote sensing of the tropical rain forest boundary layer using pulsed Doppler lidar
}

\author{
G. Pearson ${ }^{1,2}$, F. Davies ${ }^{1,3}$, and C. Collier ${ }^{3}$ \\ ${ }^{1}$ Centre for Environmental Systems Research,University of Salford Salford, Greater Manchester, M5 4WT, UK \\ ${ }^{2}$ Halo Photonics Ltd, Leigh, Worcestershire, UK \\ ${ }^{3}$ School of Earth and Environment, University of Leeds, Leeds, Yorkshire, LS2 9JT, UK \\ Received: 18 January 2010 - Published in Atmos. Chem. Phys. Discuss.: 19 February 2010 \\ Revised: 8 June 2010 - Accepted: 10 June 2010 - Published: 2 July 2010
}

\begin{abstract}
Within the framework of the Natural Environment Research Council (NERC) Oxidant and Particle Photochemical Processes (OP3) project, a pulsed Doppler lidar was deployed for a 3 month period in the tropical rain forest of Borneo to remotely monitor vertical and horizontal transport, aerosol distributions and clouds in the lower levels of the atmosphere. The Doppler velocity measurements reported here directly observe the mixing process and it is suggested that this is the most appropriate methodology to use in analysing the dispersion of canopy sourced species into the lower atmosphere. These data are presented with a view to elucidating the scales and structures of the transport processes, which effect the chemical and particulate concentrations in and above the forest canopy, for applications in the parameterisation of climate models.
\end{abstract}

\section{Introduction}

The transport of aerosols and chemical species from the surface, through the boundary layer and in to the free troposphere is governed by the dynamics within the lower levels of the atmosphere (Warneke et al., 2001; Eerdekens et al., 2009; Ganzeveld et al., 2008; Fisch et al., 2004 and VilaGuerau de Arellano et al., 2009). These dynamics have as their driving force the incoming solar radiation, the surface energy partitioning, vertical gradients of wind speed, potential temperature and moisture and the geostrophic wind. The surface and canopy of the tropical rain forest act as important sources and sinks of chemical species (Lelieveld et al., 2008). The distributions, dilutions, circulations and reactions

Correspondence to: F. Davies (f.davies@leeds.ac.uk) of these species in the boundary layer and inside the canopy are strongly influenced by these transport processes and their diurnal cycles.

The Oxidant and Particle Photochemical Processes (OP3) project is a UK university consortium programme aimed at studying these chemical and aerosol processes in and above the south east Asian tropical rainforest of north east Borneo (Hewitt et al., 2010, 2009). A comprehensive array of point sampling instrumentation was deployed in and above the forest canopy during the period April-July 2008, with support from over-flights of the UK's instrumented Facility for Airborne Atmospheric Measurement (FAAM) research aircraft. In order to provide a continuous view of the dynamics of the boundary layer, a pulsed Doppler lidar was deployed and operated on a continuous basis for the duration of the experiment. This paper presents an analysis of the data from this instrument with a view to visualising and parameterising the dynamics and structures in the tropical boundary layer and their diurnal variability. The analysis reported here presents results pertaining to the vertical velocity, aerosol distributions and the statistics of the cloud coverage.

\section{The tropical boundary layer}

The Food and Agriculture Organisation of the United Nations published an assessment of the Global Forest Resource in 2005 (www.fao.org). $30 \%$ of the global land area was reported to be forest. $36 \%$ of this was primary forest that had not been affected by human activity. However, 6 million hectares of this is being lost or modified each year. It is estimated that 283 Gigatonnes of carbon is currently retained in the forest biomass alone and that together with all the carbon in the soil, deadwood etc. this constitutes about 50\% more carbon than that in the atmosphere. Understanding current

Published by Copernicus Publications on behalf of the European Geosciences Union. 
and future influences of the forests on the atmosphere and climate is therefore important in order to enable more accurate global climate models and assessments of the future trends in the global climate. The tropics are also important sources and sinks of chemical species critical to climate change impacts (Hewitt et al., 2009).

Garrett (1982) presented an atmospheric model structured in such a way as to enable the convective boundary layer and convective cloud formation over a forested surface to be studied. It was stressed that the soil moisture content, the canopy density and the surface roughness were likely to influence the daily growth and decay of the boundary layer and the formation of convective clouds. Martin et al. (1988) used a tethered balloon, rawinsondes and an instrumented aircraft to study the Amazonian boundary layer. Their observations indicated a growth rate of the mixed layer height (MLH) in the early morning in the range $180-288 \mathrm{~m} \mathrm{hr}^{-1}$ and a maximum height of $1200 \mathrm{~m}$ at 13:00 (all times are local unless otherwise stated). They also reported residual layers persisting in the day and nightime that were not associated with any active vertical transport. Culf et al. (1997) highlighted the fact that a correctly parameterised boundary layer was important in their analysis of the $\mathrm{CO}_{2}$ concentrations over the Amazonian rain forest. They used radiosondes and tethered balloons together with a gradient of potential temperature approach to diagnose the MLH. The rate of increase in the MLH was found to be approximately $175 \mathrm{~m} \mathrm{hr}^{-1}$ between 10:00 and 14:00. The average maximum in the MLH was $1300 \mathrm{~m}( \pm 300 \mathrm{~m}, \pm 1 \sigma)$ and occurred at 17:00. The important issue of characterising the nocturnal boundary layer was also addressed and it was suggested that the relative humidity profile, rather than the potential temperature profile, was the more appropriate parameterisation tool. This analysis indicated a nocturnal boundary layer height of the order $30 \mathrm{~m}$ at 20:00, rising through the night to approximately $150 \mathrm{~m}$ at 08:00. Therefore, there was an inferred collapse rate of the MLH between 17:00 and 20:00 of $>400 \mathrm{~m} \mathrm{hr}^{-1}$. These results are summarised in Fig. 1. Parameterisation of the boundary layer and the characteristics of the mixed layer height over a higher latitude forest environment has been analysed by Joffre et al. (2001).

Fisch et al. (2004) and Fisch and dos Santos (2008) have studied the influences of season and land usage on the Amazonian boundary layer. Radiosonde data and a potential temperature gradient analysis were again employed together with sodar data. Figure 1 also shows these data. The approximate rates of increase in the mean MLH in the time intervals 08:00-11:00, 11:00-14:00 and 14:00-17:00 were 64, 210 and $64 \mathrm{~m} \mathrm{hr}^{-1}$ in the dry season and 122, 107 and $63 \mathrm{~m} \mathrm{hr}^{-1}$ in the wet season respectively. The sodar data was shown to be influence by residual layers. Vila-Guerau de Arellano et al. (2009) have studied the isoprene fluxes in the tropical rainforest environment and emphasise the importance of correctly parameterising the MLH. They found that this holds true for the correct estimation of surface fluxes us-

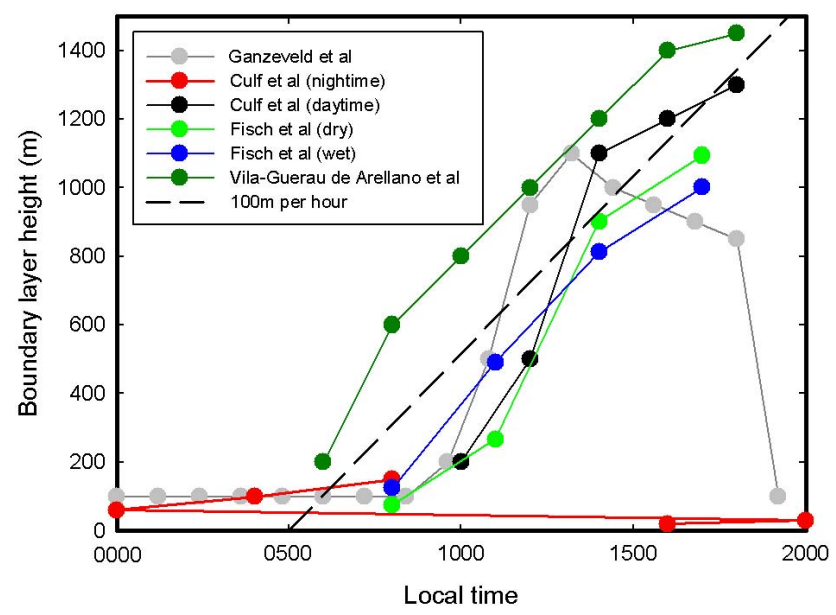

Fig. 1. A summary of previous experimental and theoretical results for the MLH above the tropical rain forest. The horizontal axis represents $20 \mathrm{~h}$ of time starting at mid-night.

ing the convective boundary budget method when direct flux measurements are not availiable. One of their concluding remarks was that continuous monitoring of the MLH using a wind profiler or lidar was recommended in order to minimise the uncertainties related to the development of the MLH and estimating the surface emission fluxes.

Ganzeveld et al. (2008) analysed nitrogen oxides, ozone and VOCs in the tropical boundary layer. They highlighted the issue that climate models had previously estimated a too shallow boundary layer over tropical forests primarily due to a misrepresentation of the surface energy balance. Their simulations suggested an increase in the MLH of $300 \mathrm{~m}$ (up to a typical maximum of $1400 \mathrm{~m}$ ) if the soil moisture stress function was adjusted to a more representative value. It was also noted that when shallow cumulus clouds formed at altitudes of $1-3 \mathrm{~km}$, the potential temperature gradient did not always indicate an explicit inversion height leading to an uncertainty in the effective MLH as derived from radiosondes. The results published for the MLH in the context of the simulated $\mathrm{HCHO}$ mixing ratio, show the diurnal variation portrayed in Fig. 1 with a nightime MLH of the order $100 \mathrm{~m}$ and an increase up to approximately $1100 \mathrm{~m}$ at local noon. The rate of increase of the MLH between 10:00 and 12:00 was approximately $225 \mathrm{~m} \mathrm{hr}^{-1}$.

Krejci et al. (2005) used radiosondes to study the Amazonian boundary layer in the context of aerosol distributions. There analysis of the MLH was based upon relatively sparse sampling but they observed heights of $800 \mathrm{~m}$ at 09:00, increasing to $1170 \mathrm{~m}$ at $11: 00$. The maximum rate of increase they observed was $360 \mathrm{~m} \mathrm{hr}^{-1}$ but a value of half this was stated as being more typical. The MLH at local noon was determined to be in the region $1200-1500 \mathrm{~m}$. In terms of their detailed aerosol results, it is interesting to note that they reported a periodic strong gradient in the $\mathrm{N}_{120}(0.12 \mu \mathrm{m})$ 
particle fraction around $400 \mathrm{~m}$, with the values below this level being 5-10 times higher than those aloft. In general their results show complicated and variable vertical profiles of the accumulation mode aerosol indicating that this alone would be an ambiguous tracer of mixed layer height. Amazonian aerosols distributions were also studied by Elbert et al. (2007). They showed that fungal wet spore discharging was a major source of coarse air particulate matter (characteristic size range $1-10 \mu \mathrm{m}$ ) and that in pristine tropical rainforest air, fungal spores may account for up to $40 \%$ of the aerosol in this mode. A diurnal variability was also identified with a $20 \%$ increase in the night. With a strong diurnal variation in the aerosol number density, care must be taken in interpreting backscatter profiles in the context of the dynamic processes in the near surface region. Primary bioaerosols emissions were studied directly by Gabey et al. (2009) during the OP3 campaign.

\section{Lidar observations of the boundary layer}

Active optical remote sensing with pulsed lidar instrumentation offers a unique view on the atmosphere. Systems are available that rely on molecular, atomic or particulate scattering and numerous modes of operation with multiple data products are possible (Weitkamp, 2005). Backscatter lidars measure the reflected light from aerosol particles in the atmosphere. The amount of backscattered signal will depend on the amount of aerosol in the atmosphere. There is an assumption that the boundary layer air has relatively high amounts of aerosol compared to the clean air above the boundary layer. In unstable boundary layers the aerosol is considered to be well mixed up to the temperature inversion that marks the top of the boundary layer or MLH. Remote sensing of the MLH with ground based lidar instrumentation has concentrated on the use of characteristic features in the vertical distribution of aerosols (Flamant et al., 1997; Menut et al., 1999; Dupont et al., 1999; Davis et al., 2000; Matthias and Bosenberg, 2002; Hennemuth and Lammertt, 2006; Haij et al., 2007). Marsik et al. (1995) presented an inter-comparison of rawinsondes, a wind profiler (with RASS) and two lidars for determination of the MLH. Considerable variability was found between the various approaches. It was noted that the lidar backscatter data and analysis consistently produced the lowest estimation of MLH. This was attributed to the fact that the aerosols that were acting as the tracer were not mixed up to the point where the rawinsondes were indicating the threshold potential temperature gradient. It was suggested that the lidars were giving an effective mixing depth but it was also emphasised that the lidar approach could give erroneous results due to residual layers and clouds.

Grimsdell and Angevine (1998) reported results comparing radar wind profiler, radiosonde and ceilometer data in the context of determining the MLH and Steyn et al. (1999) extended the (sometimes subjective) prior approaches of a critical gradient or critical absolute backscatter to include a model of the entire aerosol backscatter profile. This was shown to be a more robust technique that was better able to accommodate layering and variable gradients in the aerosol distribution. Cohn and Angevine (2000) used a combination of two lidars (one of which was a pulsed Doppler instrument) and a radar wind profiler to study the MLH and the entrainment zone. While the lidar Doppler data was shown, it was not specifically used in the analysis. The wavelet approach utilised in their analysis was shown to be problematic when clouds and residual layers were present and, to avoid ambiguities, they excluded data outside the time interval 10:0017:00. Another issue that was alluded to, that is particularly relevant to tropical environments, was the interaction of the aerosol and humidity profiles due to the possible hydrophilic nature of the aerosol.

Davies et al. (2007) reported inter-comparions of pulsed Doppler lidar data with radiosondes and the outputs of several simulations. Again, although the lidar instrument was Dopplerised, this data was not employed in the estimation of MLH. A subjective gradient of the backscatter profile approach was utilised. An important point was made here with respect to the MLH and the lifting condensation level (LCL), as parameterised in the Met Office unified model (UM). In the parameterisation scheme of the UM, for the case of cumulus capped boundary layers, the MLH is set at the LCL.

The influence of humidity on the vertical aerosol backscatter distribution was further studied within the context of convection and depolarisation by Gibert et al. (2007). Relative humidity was shown to be an important factor that influences the lidar signal since it modifies the aerosol size, shape and complex refractive index distributions. In addition, the possible hysteresis of particle size growth in a variable relative humidity field may further complicate any interpretations with respect to mixing processes.

Accordingly, they emphasise that aerosol backscatter coefficient alone cannot be directly interpreted as being a tracer for the MLH. These issues of humidity and MLH versus LCL are of particular relevance in tropical environments.

Recent field campaigns with pulsed Doppler lidar instruments have begun to show the potential of this technology for real-time observations of the boundary layer (Frehlich et al., 2006; Pearson et al., 2009 and Tucker et al., 2009). In particular, the ability of these instruments to be operated autonomously for observing the vertical motion in the lower level of the atmosphere offers the ability to visualize the vertical transport directly, without the need to infer the dynamics from secondary measurements such as aerosol distributions or potential temperature gradients. 


\section{Description of instrument and deployment}

The lidar deployed to Borneo was a 1.5 micron pulsed Doppler instrument that had previously been used for studying the boundary layer in mid-latitude, European environments. A full description of the system is given by Pearson et al. (2009). It is a commercial device manufactured by Halo Photonics Ltd. The system relies on backscatter from aerosols and provides range gated Doppler and return power measurements. From these primary data products, wind profiles, turbulence parameters, backscatter coefficients and cloud base measurements can be derived. The lidar has a minimum range of $75 \mathrm{~m}$ and maximum range of up to $6 \mathrm{~km}$ which is dependent on atmospheric aerosol concentrations. The spatial and temporal resolutions are variable but were fixed at values of $30 \mathrm{~m}$ and $2 \mathrm{~s}$ respectively for this deployment. The Doppler measurement precision is typically of the order $10 \mathrm{~cm} \mathrm{~s}^{-1}$ or less in the boundary layer (Pearson et al., 2009). The instrument was equipped with an all-sky scanner and was housed in a stand-alone enclosure. Full remote control including configuring the scan schedule, the data acquisition parameters and data off-load was achieved over the internet.

The instrument was located at the Nursery site $\left(117.859^{\circ} \mathrm{E}, 4.977^{\circ} \mathrm{N}, \mathrm{El}: 198 \mathrm{~m}\right)$ in the Danum valley region of Sabah, Borneo. The lidar site was in a valley, approximately $225 \mathrm{~m}$ below the base of the $10 \mathrm{~m}$ high Global Atmospheric Watch (GAW) tower $\left(117.844^{\circ} \mathrm{E}, 4.981^{\circ} \mathrm{N}\right.$, El: $426 \mathrm{~m}$ ) which was heavily instrumented with chemical and particulate sampling equipment for the duration of the experiment. The topography of the 44000 ha Danum valley region is hilly and consists of an undulating ground surface, with a relatively uniform virgin rain forest canopy, dissected by the Segama river and its tributaries. The highest point is Mount Danum $(1093 \mathrm{~m})$. The valleys are approximately $200 \mathrm{~m}$ deep with side wall gradients which can approach near vertical. Figure 2 shows a cross-section of the local topography around the lidar site.

The scanner was configured to take wind profiles every $0.5 \mathrm{~h}$ and to stare vertically for the intervening periods. Each ray used in the wind profile consisted of the average of the distributed return signal from 60000 consecutive laser pulses. The lidar operated at a pulse rate of $20 \mathrm{kHz}$ and therefore this was achieved using a $3 \mathrm{~s}$ stare time. The total time (including signal processing) taken to produce each wind profile was approximately $4 \mathrm{~min} 50 \mathrm{~s}$. For the vertical data, 40000 pulses were averaged per ray and the update rate was approximately once every $13.5 \mathrm{~s}$. There were therefore of the order 114 rays per vertical stare file. For both the stare and wind profile data, 200,30 m range gates were recorded.

The data collection period spanned 3 April to 20 June 2008. The weather in the Borneo region is relatively constant throughout the year. Average monthly temperatures are $25-26^{\circ} \mathrm{C}$ and there are typically $4-6 \mathrm{~h}$ of sunshine per day. At night the valleys regularly experience

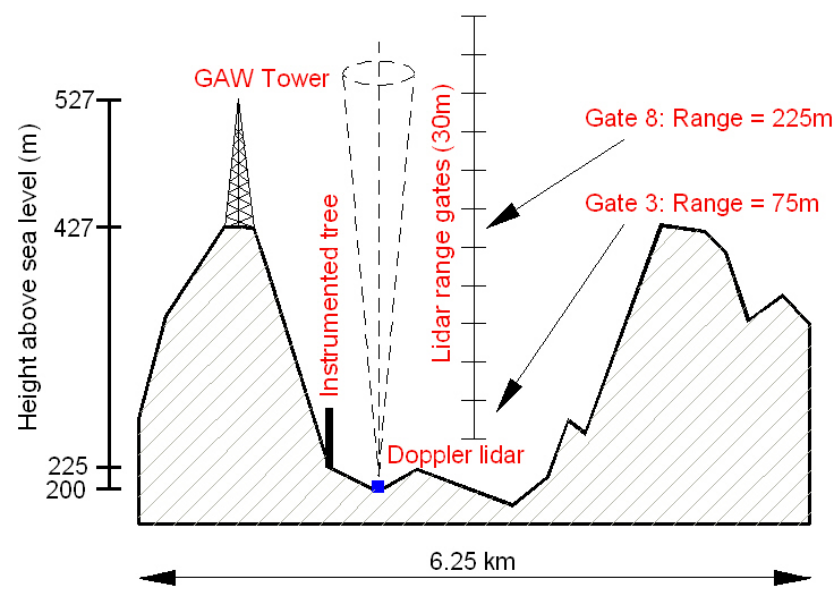

Fig. 2. A schematic cross section of the terrain around the lidar site from the NW (left) to the SE (right). Note the different vertical and horizontal scales and the location of the lidar with respect to the valley floor and the GAW tower. The location of the instrumented tree used for the in canopy measurements is also shown.

low cloud that dissipates with the onset of significant insolation in the morning. The wet season is between November and February when the average monthly rainfall approximately doubles from $250 \mathrm{~mm}$ to $500 \mathrm{~mm}$. This region is locally referred to as the "Land below the Wind" because it is located below the typhoon belt. However, the name is doubly appropriate since the near surface winds are typically low.

\section{Results and discussion}

Apart from some intermissions due to power outages, a continuous data set was obtained between 3 April and 19 June. A total of $1656 \mathrm{~h}$ of data were recorded: a testament to the autonomous capacity of the instrument since it was unttended and operated remotely for this entire period. The overall aim of the data capture and subsequent analysis was to generate a statistically valid averaged data set for use in correctly parameterising the tropical boundary layer in climate and atmospheric chemistry models.

Figure 3 shows the typical temporal and spatial evolution of convection in the mid-morning period of the tropical day as observed at the Nursery site on 24 April 2008. The upper and lower panels show the vertical velocity and aerosol backscatter respectively versus time and height for a $25 \mathrm{~min}$ period commencing at 11:00. Convective updrafts can be readily seen in the upper panel and entrained aerosol being transported therein is evident in the lower panel. The peak updraft velocity is approximately $2.5-3 \mathrm{~ms}^{-1}$. Two features of the updrafts illustrated well here are that they do not always exhibit an enhanced aerosol content and they can be seen to extend to heights well above the region where the backscatter exhibits a strong negative gradient. The fact 

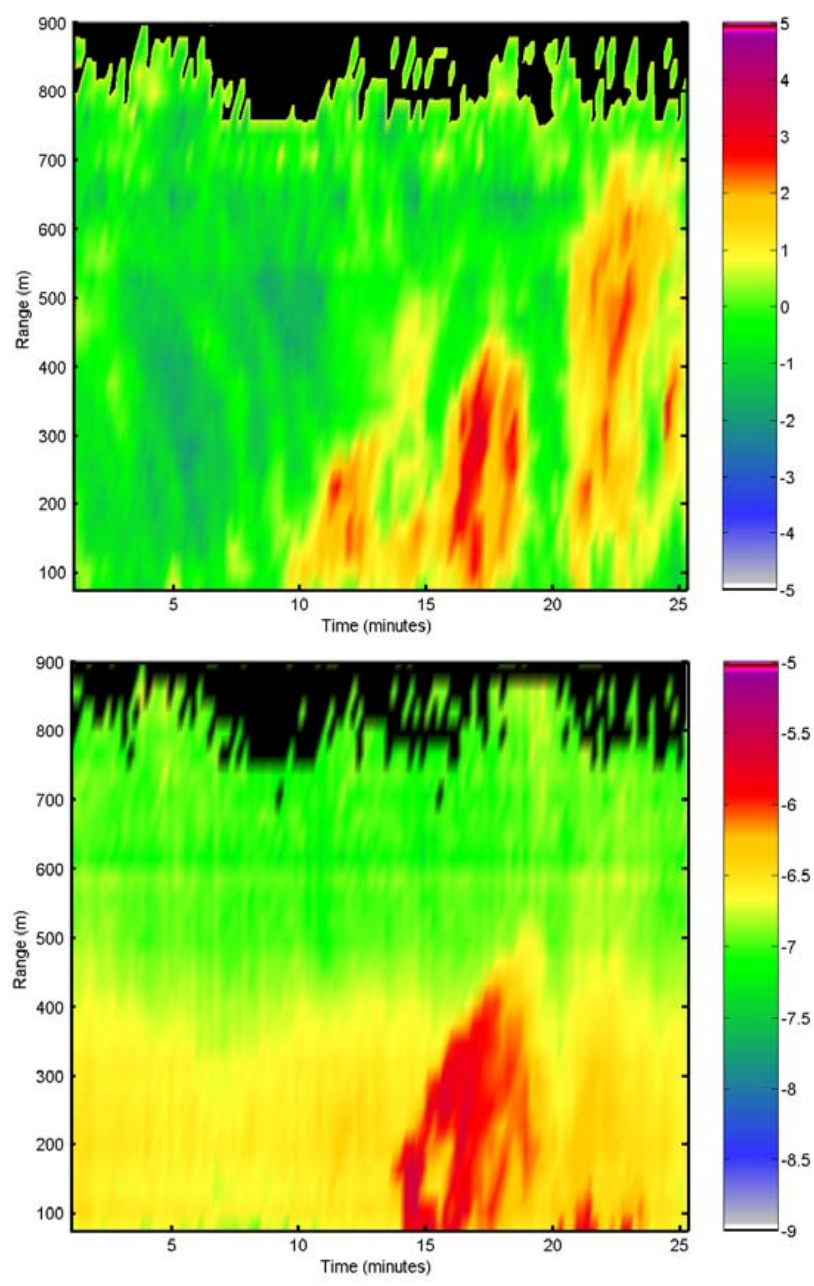

Fig. 3. An example of a 25 min observation of the vertical velocity (upper panel) and aerosol backscatter coefficient (lower panel). The start time was 11:05 LT on 24 April 2008. The colour scales in the upper and lower plots are $\mathrm{ms}^{-1}$ and log backscatter $\left(\mathrm{m}^{-1} \mathrm{sr}^{-1}\right)$ respectively. Updrafts are designated positive velocity.

that the aerosol is not always entrained in the updraft is interesting in the context of inferring the MLH from aerosol backscatter measurements. It has been noted previously that when different techniques are compared, values derived from lidar backscatter often show the lowest MLH values which is reasonable if this characteristic is prevalent. The reduction in the backscatter at around $400 \mathrm{~m}$ is not easily explained since a number of other measurements are necessary in order to know the humidity field, the aerosol particle size distributions and the aerosol type. It is worth recalling the result of Krejci et al. (2005) where the same height was alluded to in the context of a change in the characteristics of the accumulation mode aerosol distribution. Figure 4 shows the typical daily development, extent and cessation of convection activity. The period of intense convective activity can be seen to exist between 09:00 and 15:00.

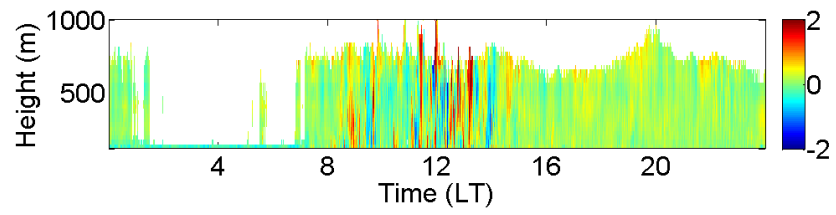

Fig. 4. An example of the daily vertical velocity field as recorded on 15 April 2008. The colour scale is $\mathrm{ms}^{-1}$, the horizontal axis is LT and the temporal resolution is $13 \mathrm{~s}$ (observation time of $2 \mathrm{~s}$ and $11 \mathrm{~s}$ of processing time). The vertical axis is height (a.g.l.) in meters.

The entire data record was analysed with a view to obtaining the statistics of the daily character of the boundary layer and cloud coverage. In this tropical environment, due to the consistent nature of the daily weather conditions, it was expected that the daily cycles of the boundary layer characteristics would show a high level of repeatability. In order to assess the stationarity of the data sets and consequently an appropriate mode of analysis, they were analysed on daily, weekly and monthly timescales and the results compared. An example of two consecutive weekly averaged data sets is shown in Fig. 5. Each 25 min vertical stare file was reduced to a single ray by averaging together the 114 rays per file. This was done twice, once including all data above the noise floor (wideband SNR $>-17 \mathrm{~dB}$ ) and again with an SNR band set to include the subset of data with SNRs in the range $-17 \mathrm{~dB}$ to $-5 \mathrm{~dB}$. The first threshold includes all data (cloud and aerosol) and the second threshold was set so as to detect the return signal predominately from aerosols, excluding clouds. The return power data was converted to attenuated backscatter values based upon the known calibration of the instrument. The vertically pointing Doppler data was analysed in terms of the standard deviation of the rangegated measurements per $25 \mathrm{~min}$ period. All the data above the noise floor was included in this analysis. The aerosol distributions were computed by taking the difference between the "all data" and "cloud only" averages. It can be seen that there is a high degree of similarity between the plots for the two successive weeks shown. This similarity was retained throughout the whole 10 week data set and stationarity testing indicated that averaging of the whole record was statistically valid. This would certainly not be the case for similar data sets over western Europe.

Figure 6 shows a contour plot of the averaged daily backscatter versus height (evaluated for the entire 10 week data collection period) as derived from the subset of data with SNR values in the range $-5 \mathrm{~dB}$ to $-17 \mathrm{~dB}$. In the lowest $900 \mathrm{~m}$, this sub-set of data corresponds predominately to returns from aerosols. Above this height, the plot shows the weak cloud returns from the aerosol - cloud interface at cloud base and the similarly weak returns from pulses that have undergone significant attenuation by virtue of a round trip path within the cloud. The region of relatively high backscatter indicated by the red region shows a growth in 

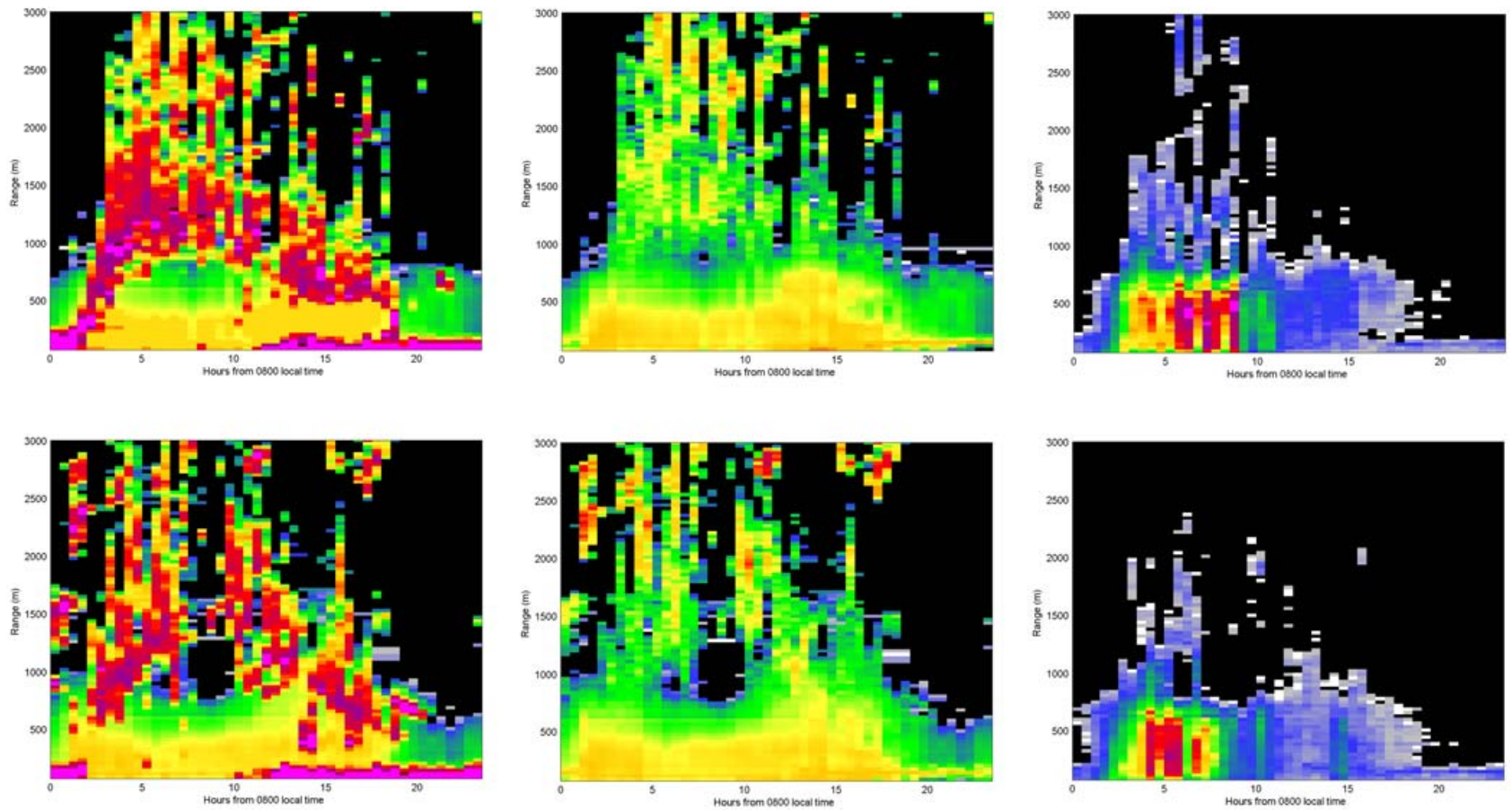

Fig. 5. These plots show diurnal cycles, as averaged over a week, for the first 2 weeks of the deployment. The top row correspond to week 1 , starting 3 April 2008, and the second row to week 2. The three columns, from the left, are backscatter value (all data with SNR $>-17 \mathrm{~dB}$ ), backscatter value (data for SNR values between $-5 \mathrm{~dB}$ and $-17 \mathrm{~dB}$ ) and standard deviation of the vertical velocity evaluated from all the data with an SNR $>-17 \mathrm{~dB}$. The backscatter colour scale is the same as shown in the lower panel of Fig. 3. The colour scale for the right hand column is as Fig. 8 but the range is $0.1-1.1 \mathrm{~ms}^{-1}$. For each panel the horizontal axis is $24 \mathrm{~h}$ starting at 08:00 LT. The vertical axis is height and extends from $75-2955 \mathrm{~m}$.

height starting at around 07:30, leading to a plateau region with an upper bound at approximately $400 \mathrm{~m}$ altitude. The rate of increase in the height of this region in the early morning was approximately $200 \mathrm{~m} \mathrm{hr}^{-1}$. There is a slight increase in the height of this region at around 18:00 and then a decay to lower levels over the time period 18:00-24:00. Above this zone, there is a fall off with height in the average backscatter level of approximately a factor 6 over the height range $400-800 \mathrm{~m}$. The lower panel of Fig. 6 shows the relative vertical gradient in the backscatter through the average day. The black lines indicate the approximate positions of the maximum gradient, the feature conventionally used for determination of the MLH. The region of large negative gradient in the day-time aerosol signal is well highlighted as is a lower layer which grows through the evening. The transition between these and the humidity/aerosol interaction gives rise to ambiguities in the interpretation of these features in the context of mixed layer height.

Figure 7 shows the averaged daily backscatter versus height (evaluated for the entire 10 week data collection period) as derived from the subset of data with SNR values $>-5 \mathrm{~dB}$. The colour scale in this case indicates the occurrence, as a percentage, where white corresponds to $1 \%$ and black is $<1 \%$. These data predominately show returns from clouds. The void in the plot roughly bounded by the times 10:00 and 18:00 and the heights $75 \mathrm{~m}$ and $700 \mathrm{~m}$ is nominally cloud free. The low level nocturnal cloud that consistently forms in the valley is readily seen between 20:00 and 08:00. It can be seen that the frequency of occurrence of the nocturnal low-level cloud is of the order $60 \%$ though the period 02:00-06:00. This observation is consistent with the visual observations from the GAW tower that indicated the valleys to be regularly in cloud in the early morning. In the rest of the parameter space, it can be seen that the frequency of cloud coverage reaches values of around $10 \%$. The zone of the plot exhibiting a slightly higher percentage value at a height of around $400 \mathrm{~m}$, starting at 18:00, corresponds to the analogous feature in the aerosol data of Fig. 6. The choice of the SNR threshold value used to split the aerosol/cloud returns clearly influences how this feature appears in these two figures and again highlights the issue of unambiguously interpreting the backscatter gradients. It seems reasonable that the aerosol feature is coupled to a humidity effect and reflects those occasions where the humidity was approaching that required for large-scale nucleation of cloud droplets. 

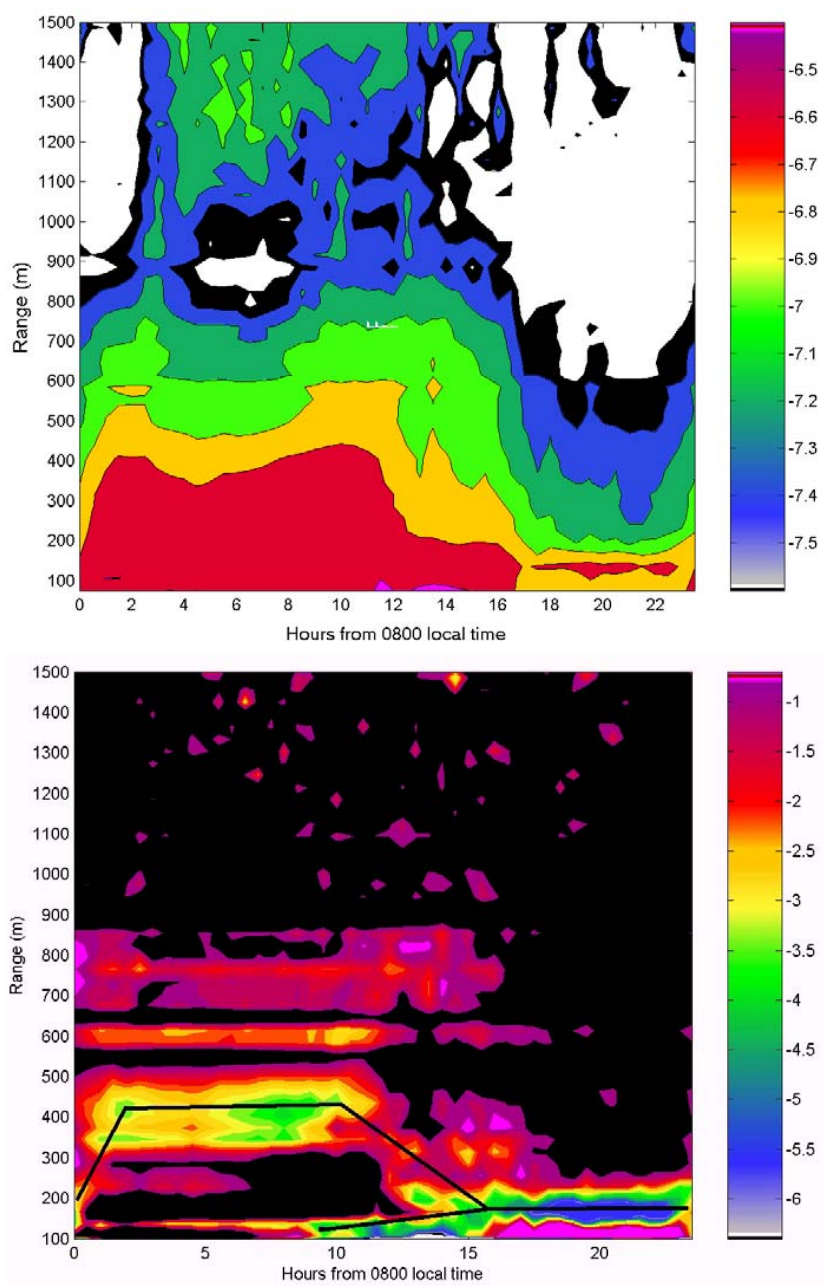

Fig. 6. Upper panel: Contour plot of the averaged daily backscatter versus height (evaluated for the entire 10 week data collection period) as derived from the subset of data with SNR values in the range $-5 \mathrm{~dB}$ to $-17 \mathrm{~dB}$. The contours are at $2 \mathrm{~dB}$ intervals. The horizontal axis is $24 \mathrm{~h}$ starting at 08:00. The colour bar scale is $\log 10$ backscatter coefficient $\left(\mathrm{m}^{-1} \mathrm{sr}^{-1}\right)$. Lower panel: Same data set re-plotted in terms of the relative gradient of the backscatter versus range. The black lines indicate the approximate positions of the regions of maximum gradient through the day.

Figure 8 shows the average diurnal cycle in the standard deviation of the vertical velocity versus height. This plot was produced by analysing all the data above the SNR threshold of $-17 \mathrm{~dB}$. The standard deviations were computed for each $25 \mathrm{~min}$ vertical stare data segment and then successive days were averaged. It can be seen that these data portray a clear picture of the average temporal and spatial pattern of the diurnal cycle in the vertical mixing without the ambiguities associated with interpreting aerosol backscatter levels. The zone comprising the green, yellow and red colours can be seen to exhibit a degree of correlation with the cloud free zone of Fig. 7 but shows different behaviour to that reflected

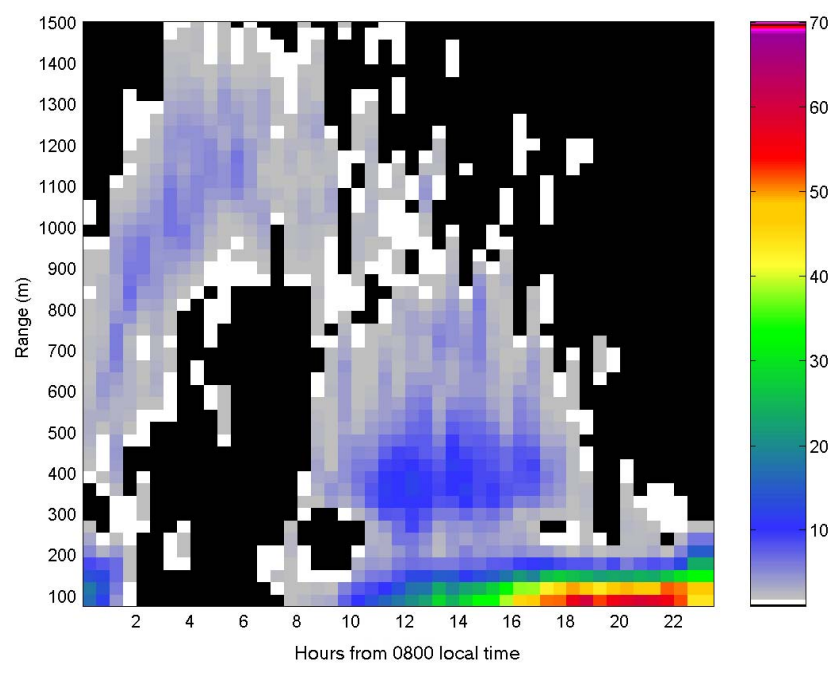

Fig. 7. The statistics of the cloud coverage for the whole 10 week period as evaluated from the subset of data with an SNR $>-5 \mathrm{~dB}$. The colour bar indicates $\%$ of time. White corresponds to $1 \%$ and black is $<1 \%$.

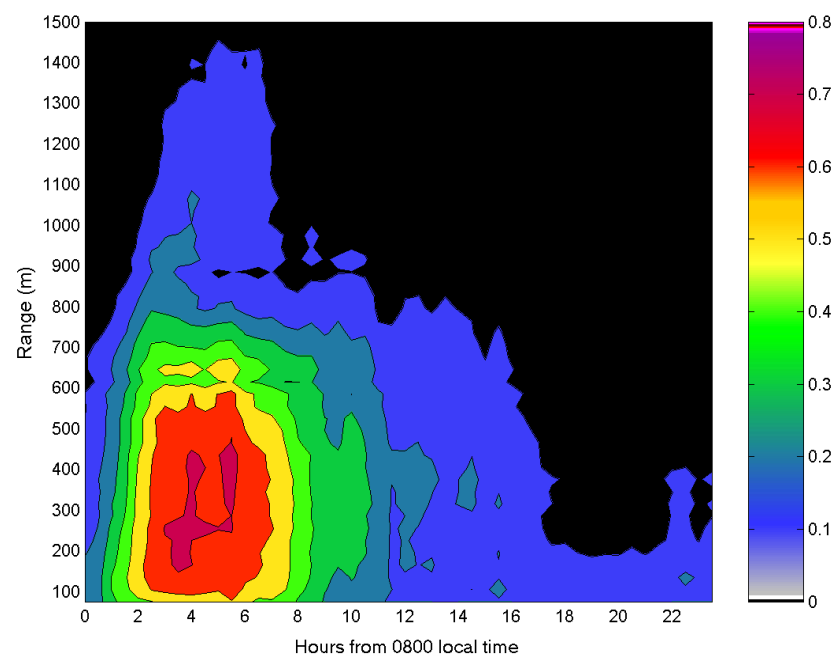

Fig. 8. A contour plot of the average standard deviation of the vertical velocity evaluated from the entire 10 week data collection period. All SNR values $>17 \mathrm{~dB}$ are included. The contours are every $0.1 \mathrm{~ms}^{-1}$

in the gradient of the aerosol field. This is consistent with the model approach of Davies et al. (2007) where the MLH and the LCL were matched for cumulus capped boundary layers. For the purposes of comparison, the $0.3 \mathrm{~ms}^{-1}$ contour is replotted in Fig. 10.

For the duration of the deployment, twice per hour, a wind profile was determined by conically scanning the beam over 12 individual inclined lines-of-sight. The mean, maximum and standard deviation of the wind speed versus height, as recorded at local noon, for the duration of the deployment, are shown in Fig. 9. The maximum winds were relatively 


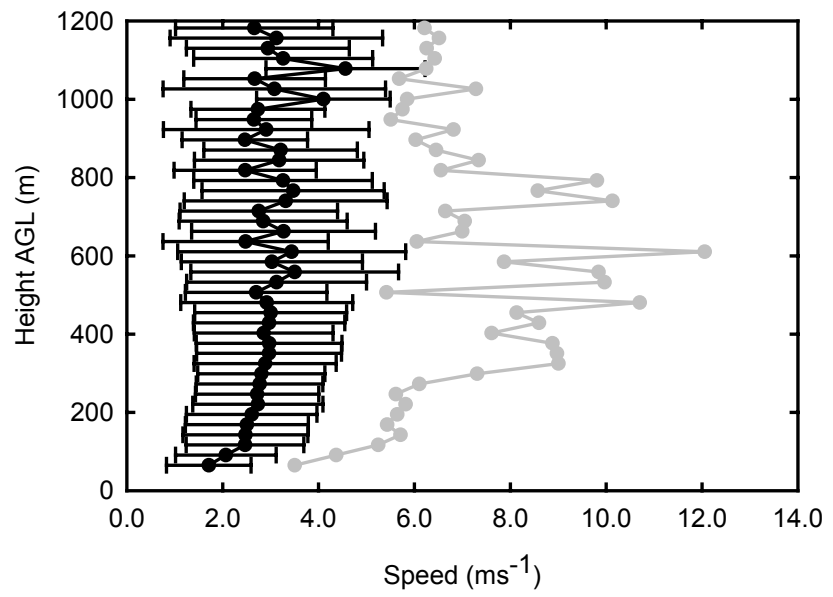

Fig. 9. The mean (black circles), maximum (grey circles) and standard deviation (error bars on the mean plot) of the horizontal wind speed versus height for the period 3 April 2008-20 June 2008 as recorded daily over the time interval 12:00-12:05.

high because of the gusts associated with thunderstorm outflows. Shear can seen in the region near the ground, which is also below the valley rim. Above this, the average speed is approximately constant with height at around $3 \mathrm{~ms}^{-1}$. The typical values of the vertical velocity during active mixing are therefore similar to those of the horizontal flow, consistent with the phrase the "land below the wind".

Figure 10 shows a review of the diurnal MLH variation as characterised by various analyses of the pulsed Doppler lidar data acquired during the 10 week deployment. The blue plot shows the profile in the maximum gradient of the backscatter. This metric is influenced by humidity, residual layers and is un-representative through the night. The green line represents the level indicated by the cloud base where we have used an occurrence of 5\% as the threshold. The red and black data are derived from the vertical velocity statistics and are based upon the regions where the vertical velocity was greater than $0.5 \mathrm{~ms}^{-1} 2 \%$ (black) and $10 \%$ (red) of the time respectively. The yellow points are based upon the $0.3 \mathrm{~ms}^{-1}$ contour of the averaged standard deviation in the vertical velocity. The two dashed lines show rates of $100 \mathrm{~m} \mathrm{hr}^{-1}$ and $350 \mathrm{~m} \mathrm{hr}^{-1}$. All the different approaches show a growth rate in the morning close to the $350 \mathrm{~m} \mathrm{hr}^{-1}$ rate. The previous published data which best agrees with these observations is that of Ganzeveld et al. (2008) which was a diagnostically calculated MLH from a single column chemistry model. The other previous data sets appear to show slower growth rates. The collapse to the nocturnal state shows similar behaviour in the cloud, standard deviation and thresholded Doppler data (red plot, $10 \%$ of the time vertical velocity $>0.5 \mathrm{~ms}^{-1}$ ). The nocturnal MLH is not well characterised by the lidar since the minimum range of the data is $75 \mathrm{~m}$ and the valley is predominately cloud bound during this period. However, the lidar data does indicate that the there is negligible vertical

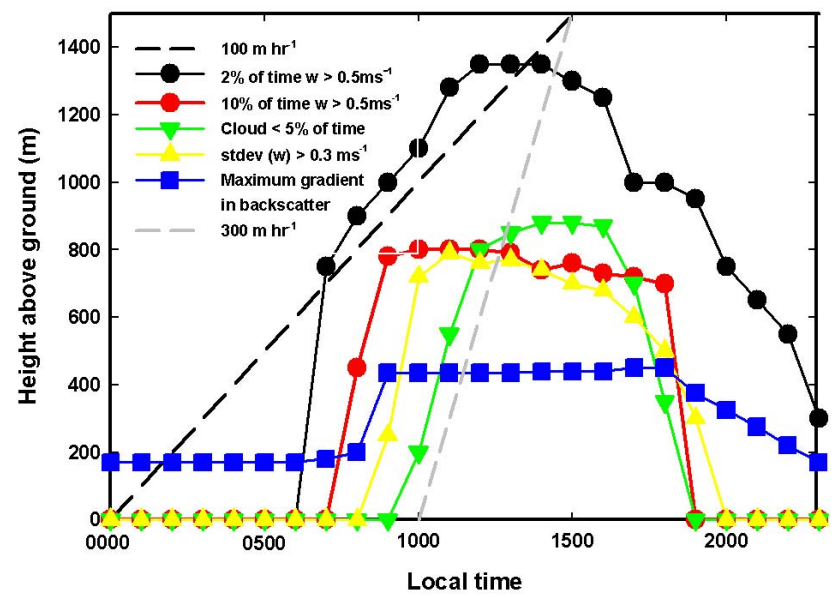

Fig. 10. A summary of the various modes of data analysis that have been used to paramaterise the structure of the tropical boundary layer. See discussion section for details.

motion in the nocturnal low cloud region implying that there is little vertical transport at night. This does not preclude the possibility of localised nocturnal valley and drainage flows that may be active in the region below $75 \mathrm{~m}$.

The fact that the lidar was located in the bottom of one of the many valleys in the region means that the data and particularly the nocturnal data are only applicable to this portion of the terrain. It would be expected that the ridges between the valleys (i.e., where the GAW tower is located) will be influenced more by the horizontal flow and will be subject to different nocturnal conditions since they are above the low lying cloud. Because of the lack of mixing and the nature of stable boundary layer flows it is impossible to measure average nocturnal flows over large areas. For this reason any measurement made in stable conditions will only be representative of a small area. Consequently to measure nocturnal conditions meaningfully in such a highly heterogeneous landscape you would need a much denser network of sensors.

\section{Conclusions and implications for modeling}

Within the frame work of the OP3 experiment, a pulsed Doppler lidar system has been deployed to the rain forest of north east Borneo in order to characterise the tropical boundary layer. The transport of chemical species and particulates from the surface and canopy layers of the forest into the lower levels of the atmosphere is governed by the dynamics of boundary layer. The lidar can remotely measure these characteristics providing a data set which allows the surface based point sampling measurements to be further analysed within the wider context of the regional atmosphere.

The range gated backscatter and vertical velocity data from the lidar have been analysed with a view to compiling a climatology that can be used in interpreting and extrapolating 
the surface and tower based point measurements. Repeatable daily cycles in the aerosol backscatter, vertical velocity and cloud base profiles have been shown to exist thereby justifying the use averaged parameters in further analyses.

Within numerical weather prediction, NWP, models MLH (or boundary layer height, BLH, or boundary layer depth, BLD) is a variable that is determined from boundary layer parameterizations. Within the Unified Model, UM, there are two parameterizations that influence the MLH: the boundary layer turbulence scheme and the convection scheme (Martin et al., 2000). Mixing determined by these two schemes can be either coupled or uncoupled. The depth to which aerosols can be mixed is then dependent on whether the boundarylayer-surface-driven mixing, as determined by the boundary layer turbulence scheme, interacts with the upper-levelcumulus-cloud- driven mixing, as determined by the convection scheme. In this way the model describes mixing from the surface as the MLH grows through the morning hours up to the Lifting Condensation Level, LCL. When cloud is determined to be present then the maximum height of turbulent mixing is considered to be then the cloud top. Martin et al. (2000) showed that cloud amount, cloud thickness, and cloud base height, as well as surface temperature and wind speed were all effected by improving the UM boundary layer turbulence scheme. However it was noted that there was a significant improvement in these parameters also from increasing the vertical resolution within the boundary layer of the model.

The vertical gradient of the aerosol backscatter, cloud base, vertical velocity distributions and the standard deviation of vertical velocity approaches to characterising the MLH have been compared for the same 70 day long data collection period in the nominal dry season. The different techniques have been summarised and the results should enable a refinement of the way in which the tropical boundary layer is parameterized. There are important differences in the rates of increase and decay in the MLH and in the measured characteristics at nighttime for the different methods of data analysis. Interpretation of the aerosol backscatter data is shown to be complicated by the influences of clouds and humidity. Cloud processes will mix clean air from above into the aerosol laden air below and could cause the reduction in aerosol concentrations within the boundary layer seen in this study. It is important to note, as discussed above, that it is the mixing that is parameterized in NWP models. This mixing then determines other variables such as the surface wind and temperature. The Doppler velocity measurements reported here are a direct measurement of the mixing process and it is suggested that this is the most appropriate methodology to use in analysing the dispersion of canopy sourced species into the lower atmosphere. It is also proposed that secondary indicators used for the determination of MLH such as radiosondes, backscatter lidar profiles and wind profilers will, on occasions, not indicate the actual active mixing height but either the height to which mixing would occur if the process was initiated or the mixing height that was appropriate in the recent past. Sporadic daytime solar occultation by clouds, shadowing within valleys, sunrise, sunset and aerosol/humidity interactions are examples of situations when this issue might be important. The other parameter measured directly by the lidar is the cloud base height. This can be compared directly to LCL as determined by NWP models. As mentioned previously the mixing at the surface modifies the $\mathrm{LCL} / \mathrm{cloud}$ base height by providing moisture and thus a comparison of LCL/Cloud base height with model results can be used as a verification of turbulence mixing schemes (provided that moisture availability is correctly modeled).

It is envisaged that these experimentally determined spatial and temporal characteristics in the averaged diurnal vertical velocity, cloud and aerosol statistics in the tropical boundary layer will find applications in the parameterisation of global climate and atmospheric chemistry models (Pugh et al., 2010).

Acknowledgements. We would like to thank the staff at the Nursery site, the Danum valley field station and all those members of the OP3 team you offered their help and support in both the preparation and execution of the experiment. The Salford Doppler lidar is part of the NERC National Center for Atmospheric Measurement (NCAS) Facility for Ground based Atmospheric Measurement (FGAM). Some support for this deployment was provided by NCAS. This is paper 509 of the Royal Society's South East Asian Rainforest Research Programme. The OP3 project was funded by the UK Natural Environmental Research Council (NE/D002117/1).

Edited by: R. MacKenzie

\section{References}

Cohn, S. A. and Angevine, W. M.: Boundary layer height and entrainment zone thickness measured by lidars and wind-profiling radars, J. Appl. Meteor, 39, 1233-1247, 2000.

Culf, A. D., Fisch, G., Malhi, Y. and Nobre, C.C.: The influence of the atmospheric boundary layer on carbon dioxide concentrations over a tropical forest, Agricultural and forest meteorology , 85, 149-158, 1997.

Davis, K. J., Gamage, N., Hagelberg, C. R., Kiemble, C., Lenschow, D. H., and Sullivan, P. P.: An objective method for deriving atmospheric structure from airborne lidar observations, J. Atmos. Ocean Tech., 17, 1455-1468, 2000.

Davies, F., Middleton, R. R., and Bozier, K. E.: Urban air pollution modelling and measurements of boundary layer height, Atmos. Environ., 41, 4040-4049, 2007.

Dupont, E., Menut, L., Carissim, B., Pelon, J., and Flamant, P.: Comparison between the atmospheric boundary layer in Paris and its rural suburbs during the ECLAP experiment, Atmos. Environ., 33, 979-994, 1999.

Eerdekens, G., Ganzeveld, L., Vilà-Guerau de Arellano, J., Klüpfel, T., Sinha, V., Yassaa, N., Williams, J., Harder, H., Kubistin, D., Martinez, M., and Lelieveld, J.: Flux estimates of isoprene, methanol and acetone from airborne PTR-MS measurements 
over the tropical rainforest during the GABRIEL 2005 campaign, Atmos. Chem. Phys., 9, 4207-4227, doi:10.5194/acp-9-42072009, 2009.

Elbert, W., Taylor, P. E., Andreae, M. O., and Pöschl, U.: Contribution of fungi to primary biogenic aerosols in the atmosphere: wet and dry discharged spores, carbohydrates, and inorganic ions, Atmos. Chem. Phys., 7, 4569-4588, doi:10.5194/acp-7-4569-2007, 2007.

Fisch, G. and dos Santos, L. A. R.: Estimates of the height of the boundary layer using Sodar and rawinsoundings in Amazonia, 14th Symposium for the advancement of boundary layer remote sensing, IOP Conference series: Earth and Environmental Science, 1, 2008.

Fisch, G., Tota, J., Machado, L. A. T., Silva Dias, M. A. F., Lyra, R. F. da F., Nobre, C. A., Dolman, J., and Gash, J. H. C.: The convective boundary layer over pasture and forest in Amazonia, Theor. Appl. Climatol., 78, 47-59, 2004.

Flamant, C., Pelon, J., Flamant, P. H., and Durand, P.: Lidar determination of the entainment zone thickness at the top of the unstable marine atmospheric boundary layer, Bound.-Lay. Meteorol., 83, 247-284, 1997.

Frehlich R., Millier, Y., Jensen, M. L., and Balsley, B.: Measurements of boundary layer profiles in an urban environment, J. Appl. Meteorol. Clim., 45, 821-837, 2006.

Gabey, A. M., Gallagher, M. W., Whitehead, J., Dorsey, J. R., Kaye, P. H., and Stanley, W. R.: Measurements and comparison of primary biological aerosol above and below a tropical forest canopy using a dual channel fluorescence spectrometer, Atmos. Chem. Phys., 10, 4453-4466, doi:10.5194/acp-10-4453-2010, 2010.

Ganzeveld, L., Eerdekens, G., Feig, G., Fischer, H., Harder, H., Königstedt, R., Kubistin, D., Martinez, M., Meixner, F. X., Scheeren, H. A., Sinha, V., Taraborrelli, D., Williams, J., VilàGuerau de Arellano, J., and Lelieveld, J.: Surface and boundary layer exchanges of volatile organic compounds, nitrogen oxides and ozone during the GABRIEL campaign, Atmos. Chem. Phys., 8, 6223-6243, doi:10.5194/acp-8-6223-2008, 2008.

Garrett, A. J.: A parameter study of interactions between convective clouds, the convective boundary layer and a forested surface, Mon. Weather Rev., 110, 1041-1059, 1982.

Gibert, F., Cuesta, J., Yano, J-I., Arnault, N., and Flamant, P. H.: On the correlation between convective plume updrafts and downdrafts, lidar reflectivity and depolarization ratio, Bound.-Lay. Meteorol., 125, 553-573, 2007.

Grimsdell, A. W. and Angevine, W. M.: Convective boundary layer height measurement with wind profilers and comparison to cloud base, J. Atmos. Ocean Tech., 15, 1331-1338, 1998.

Haij, M. J. de, Klein Baltink, H., and Wauben, W. M. F.: Continuous mixing layer height determination using the LD-40 ceilometer: a feasibility study, Scientific Report WR 2007-01, KNMI, De Bilt, 2007.

Hennemuth, B. and Lammert, A.: Determination of the atmospheric boundary layer height from radiosonde and Lidar backscatter, Bound.-Lay. Meteorol., 120, 181-200, 2006.

Hewitt, C. N., Lee, J. D., MacKenzie, A. R., Barkley, M. P., Carslaw, N., Carver, G. D., Chappell, N. A., Coe, H., Collier, C., Commane, R., Davies, F., Davison, B., DiCarlo, P., Di Marco, C. F., Dorsey, J. R., Edwards, P. M., Evans, M. J., Fowler, D., Furneaux, K. L., Gallagher, M., Guenther, A., Heard, D. E., Helfter, C., Hopkins, J., Ingham, T., Irwin, M., Jones,
C., Karunaharan, A., Langford, B., Lewis, A. C., Lim, S. F., MacDonald, S. M., Mahajan, A. S., Malpass, S., McFiggans, G., Mills, G., Misztal, P., Moller, S., Monks, P. S., Nemitz, E., Nicolas-Perea, V., Oetjen, H., Oram, D. E., Palmer, P. I., Phillips, G. J., Pike, R., Plane, J. M. C., Pugh, T., Pyle, J. A., Reeves, C. E., Robinson, N. H., Stewart, D., Stone, D., Whalley, L. K., and Yin, X.: Overview: oxidant and particle photochemical processes above a south-east Asian tropical rainforest (the OP3 project): introduction, rationale, location characteristics and tools, Atmos. Chem. Phys., 10, 169-199, doi:10.5194/acp-10169-2010, 2010.

Hewitt, C. N., MacKenzie, A. R., Di Carlo, P., Di Marco, C. F., Dorsey, J. R., Evans, M., Fowler, D., Gallagher, M. W., Hopkins, J. R., Jones, C. E., Langford, B., Lee, J. D., Lewis, A. C., Lim, S. F., McQuaid, J., Misztal, P., Moller, S. J., Monks, P. S., Nemitz, E., Oram, D. E., Owen, S. M., Phillips, G. J., Pugh, T. A. M., Pyle, J. A., Reeves, C. E., Ryder, J., Siong, J., Skiba, U., and Stewart, D. J.: Nitrogen management is essential to prevent tropical oil palm plantations from causing ground-level ozone pollution, P. Natl. Acad. Sci. USA, 106, 18447-18451, 2009.

Joffre, S. M., Kangas, M., Heikinheimo, M., and Kitaigorodskii, S. A.: Variability of the stable and unstable atmospheric boundarylayer height and its scales over a Boreal forest, Bound.-Lay. Meteorol., 99, 429-450, 2001.

Krejci, R., Ström, J., de Reus, M., Williams, J., Fischer, H., Andreae, M. O., and Hansson, H.-C.: Spatial and temporal distribution of atmospheric aerosols in the lowermost troposphere over the Amazonian tropical rainforest, Atmos. Chem. Phys., 5, 1527-1543, doi:10.5194/acp-5-1527-2005, 2005.

Lelieveld, J., Butler, T. M., Crowley, J. N., Dillon, T. J., Fischer, H., Ganzeveld, L., Harder, M, Lawrence, M. G., Martinez, M., Taraborrelli, D., and Williams, J.: Atmospheric oxidation capacity sustained by a tropical forest, Nature, 452, 737-740, 2008.

Marsik, F. J., Fischer, K. W., McDonald, T. D. and Samson, P. J.: Comparison of methods for estimating mixing height used during the 1992 Atlanta filed intensive, J. Appl. Meteorol, 34, 18021814, 1995.

Martin, G. M., Bush, A. R., Brown A. R., Lock A. P., and Smith R. N. B.: A new boundary layer mixing scheme. Part II: Tests in climate and mesoscale models., Mon. Weather Rev., 128, 32003217, 2000.

Martin, C. L., Fitzjarrald, D., Garstang, M., Greco, S., Oliveira, P. A., and Browell, E.: Structure and growth of the mixing layer over the Amazonian rain forest, J. Geophys. Res. 93, 1361-1375, 1988.

Matthias, V. and Bösenberg, J.: Aerosol climatology for the planetary boundary layer derived from regular lidar measurements, Atmos. Res., 63, 221-245, 2002.

Menut, L., Flamant, C., Pelon, J., and Flamant, P. H.: Urban boundary-layer height determination from lidar measurements over the Paris area, Appl. Optics, 38, 945-954, 1999.

Pearson, G. N., Davies, F., and Collier, C.: An analysis of the performance of the UFAM pulsed Doppler lidar for observing the boundary layer, J. Atmos. Ocean Tech., 26, 240-250, 2009.

Pugh, T. A. M., MacKenzie, A. R., Hewitt, C. N., Langford, B., Edwards, P. M., Furneaux, K. L., Heard, D. E., Hopkins, J. R., Jones, C. E., Karunaharan, A., Lee, J., Mills, G., Misztal, P., Moller, S., Monks, P. S., and Whalley, L. K.: Simulating atmospheric composition over a South-East Asian tropical rainforest: 
performance of a chemistry box model, Atmos. Chem. Phys., 10, 279-298, doi:10.5194/acp-10-279-2010, 2010.

Steyn, D. G., Baldi, M., and Hoff, R. M.:The detection of mixed layer depth and entrainment zone thickness from lidar backscatter profiles, J. Atmos. Ocean Tech., 16, 953-959, 1999.

Tucker, S. C., Brewer, Wm. A., Banta, R. M., Senff, C. J., Sandberg, S. P., Law, D. C., Weickmann, A., and Hardesty, R. M. :Doppler lidar estimation of mixing height using turbulence, shear, and aerosol profiles, J. Atmos. Ocean Tech., 26, 673-688, 2009.

Vilà-Guerau de Arellano, J., van den Dries, K., and Pino, D.: On inferring isoprene emission surface flux from atmospheric boundary layer concentration measurements, Atmos. Chem. Phys., 9, 3629-3640, doi:10.5194/acp-9-3629-2009, 2009.
Warneke, C., Holzinger, R., Hansel, A., Jordan, A., Lindinger, W., Pöschl, U., Williams, J., Hoor, P., Fischer, H., Crutzen, P. J., Scheeren, H. A., and Lelieveld, J.: Isoprene and Its oxidation products methyl vinyl ketone, methacrolein, and isoprene related peroxides measured online over the tropical rain forest of Surinam in March 1998, J. Atmos. Chem., 38, 167-185, 2001.

Weitkamp, C. (Ed.): Lidar: Range resolved optical remote sensing of the atmosphere, Springer Series in Optical Sciences, 2005. 